\title{
Significant Factors of the Successful Lean Six-Sigma Implementation
}

\author{
Ljubisa Papic* \\ University of Kragujevac \\ Faculty of Technical Sciences \\ Cacak, Serbia and \\ DQM Research Center, Prijevor, Serbia \\ dqmcenter@mts.rs \\ ${ }^{*}$ Corresponding autor \\ Mihailo Mladjenovic \\ University of Toronto SCS \\ The Sensei Group \\ Aurora, Canada \\ michael.mladjenovic@thesenseigroup.com \\ Andres Carrion Garcia \\ Polytechnic University of Valencia \\ Department of Statistics \\ Operation Research and Quality, Valencia, Spain \\ acarrion@eio.upv.es \\ Deepti Aggrawal \\ Keshav Mahavidyalaya \\ University of Delhi \\ Delhi- 110034, India \\ deepti.aggrawal@gmail.com
}

(Received September 29, 2016; Accepted November 30, 2016)

\begin{abstract}
Based on an extensive literature review we have selected factors critical for Lean Six Sigma implementation success. Four variables were selected to be used as output variables measuring this project success: project on time completion, achievement of financial goals, sigma level achieved (that was measured using Defects per Million Opportunities, DPMO), and overall project success. Using empirical data from 256 Lean Six Sigma Projects, we present the model developed and identify significant factors for Lean Six Sigma implementation success. Empirical results, which were collected during Lean Six Sigma implementation in 39 business units of an Automotive Sector Company in North America and Europe, were analysed using Multivariate Analysis of Variance (MANOVA) and General Linear Model (GLM). Two main factors were found as positively linked with the different aspects of project success: the competency of the Black Belts team and the management support to the project.
\end{abstract}

Keywords- Lean six sigma, Success factors, Statistical modeling, Six sigma project.

\section{Introduction}

The Lean Six Sigma methodology is the most effective continuous improvement approach that can support an organization to maintain its competitive position in the global market, and achieve business goals and organizational excellence. For example, we can quote Dan G. Colton, Executive Vice President, Corporate Quality at Seagate, who stated (Brue, 2000; Brue, 2002): "In terms of a system that can be deployed across all elements of our business, we found no other system that could accomplish what Six Sigma can. The Six Sigma extends well beyond 
International Journal of Mathematical, Engineering and Management Sciences

Vol. 2, No. 2, 85-109, 2017

https://dx.doi.org/10.33889/IJMEMS.2017.2.2-009

traditional quality systems in the areas of comprehensive resources training, methodology tools for execution, focus on financial improvement versus the traditional quality metrics, and the ability to be deployed across all business functions. In today's market organization's need to continuously improve their processes in order to achieve strategic and financial goals and objectives. Management leadership is a critical enabling factor necessary for successful Lean Six Sigma implementation, and associated management of the intellectual capital created during improvement activities". A similar description is given by Prudential Securities: "Six Sigma programs simultaneously benefit both the profitability of a company and its sales growth by enabling it to take market share as a preferred supplier in its industry. The benefits of Six Sigma are multifaceted. Six Sigma drives top-line growth, increases operating margins, expands cash flow, reduces working capital requirements and capital spending needs, frees up additional production capacity and enhances growth when the economy is not doing well, by improving a company's prospects of becoming a customer's preferred supplier".

\section{Six Sigma Implementation: An Historical Review}

The Six Sigma continuous improvement strategy has emerged as a response to the need of manufacturing organizations to stay competitive by improving their quality, reducing process variability, and reducing the cost of poor quality. Motorola and General Electric (GE) were some of the companies that were implementation pioneers, and Six Sigma adoption, popularity, and success are closely related to Jack Welch, former GE President.

From an historical perspective, there are four Six Sigma development stages:

- During the 1980s, Six Sigma was an initiative related to technical dimensions/aspects of variability reduction.

- During the 1990s, General Electric shifted its Six Sigma implementation focus from quality improvement to a corporate-wide program that involved the whole organization. Implementation focus shifted to cost reduction and financial results.

- During the 2000s, Six Sigma becomed the most significant business improvement methodology implemented in all types of organizations.

- In 2010, Six Sigma integrated with Lean and Innovation.

A more detailed implementation specific to the automotive industry is presented in the Table 1.

\begin{tabular}{|l|l|}
\hline Year & \multicolumn{1}{|c|}{ Event } \\
\hline \hline 1983 & Bill Smith started implementation of Six Sigma in Motorola. \\
\hline 1984 & Dr. Mikel Harry enhanced LSS implementation in Motorola by introducing "Breakthrough" strategy approach. \\
\hline 1985 & Dr. Mikel Harry published book "The Nature of Six Sigma" and started the Six Sigma Research Institute. \\
\hline 1987 & Motorola officially started Six Sigma implementation. \\
\hline 1988 & Texas Instruments started Six Sigma implementation. \\
\hline 1993 & Richard Schroeder left Motorola and joined Asea Brown Boveri (ABB). ABB started Six Sigma implementation. \\
\hline 1994 & $\begin{array}{l}\text { Dr. Mikel Harry left Motorola and joined ABB. Dr. Mikel Harry started Six Sigma Academy (SSA). } \\
\text { Richard Schroeder moved to AlliedSignal. AlliedSignal started Six Sigma implementation. }\end{array}$ \\
\hline 1995 & General Electric and GenCorp started Six Sigma implementation. \\
\hline 1996 & Siebe-PLC, Nokia, Lockheed Martin, Crane Co., Navistar, Polaroid and Bombardier started Six Sigma implementation. \\
\hline 1997 & DuPont and Libbey-Owens-Ford started Six Sigma implementation. \\
\hline 1998 & SSA started partnership with American Society for Quality and Minitab. \\
\hline 1999 & Johnson Controls and Lear started Six Sigma implementation. \\
\hline 2000 & Magna International and Intier Interiors started Six Sigma implementation. \\
\hline 2000 & Ford Motor Co. started Six Sigma implementation. \\
\hline 2001 & ASQ started Six Sigma certification and training. \\
\hline
\end{tabular}

Table 1. An historical overview of the Six Sigma implementation in the automotive industry 
International Journal of Mathematical, Engineering and Management Sciences

Vol. 2, No. 2, 85-109, 2017

https://dx.doi.org/10.33889/IJMEMS.2017.2.2-009

Towards the late 1990s, service organizations started to adopt the Lean Six Sigma methodology, demonstrating the versatile capability of the Lean Six Sigma methodology to be implemented in different industries.

\section{Lean Six Sigma Synergy}

Lean implementation is based on Toyota Production System principles developed by Taiichi Ohno (Ohno, 1988). The objective of lean organizations is achievement of quality goals, improved delivery (lead times), and reduction of operation costs. Empirical results indicate that organizations which implement Lean could achieve the following benefits: 50\% labour cost reduction, $50 \%$ defect reduction, 33\% overhead cost reduction, 50\% required space reduction and $10 \%$ increase in capacity. The key characteristics of the lean organizations which enable these improvements are elimination of non-value-added activities and waste, improved flow, and pull.

Lean system implementation occurs at each level and throughout the organization. At the strategic level, senior leaders establish - based on a review of strategic goals and objectives, Lean metrics and a Value Stream Analysis - key strategic goals and initiatives. Using Hoshin-Kanri strategy deployment methodology and associated "Catch the Ball Process", these goals and objectives are shared, reviewed and agreed upon at all levels of the organization.

Improvement activities start by identification of value from the customer's standpoint, which is followed by understanding of the value stream that creates customer's value. Customer value increase is achieved by elimination of waste. The process of waste identification starts with value stream and process-mapping and understanding the following: What are we doing? Why do we do it? How well do we do it? What is the impact of each process step on costs and customer satisfaction? Is this value-added activity? Based on an analysis of the value stream (Rother and Shook, 1998), a number of Kaizen/rapid improvement events may be conducted in order to achieve flow, pull and finally, perfection.

Lean methodology identifies seven original types of waste and the eighth is employee talent and engagement.

The original seven types of waste ("muda") are:

(i) Transport (moving products that are not actually required to perform the processing).

(ii) Inventory (all components, work in process and finished product not being processed).

(iii) Motion (people or equipment moving or walking more than is required to perform the processing).

(iv) Waiting (waiting for the next production step, interruptions of production during shift change).

(v) Overproduction (production ahead of demand).

(vi) Over processing (resulting from poor tool or product design creating activity).

(vii) Defects (the effort involved in inspecting for and fixing defects.

Some of the Lean tools that may be utilized during Kaizen activities include:

(i) Line balancing: synchronizing cycle times of process elements.

(ii) Waste elimination.

(iii) Single Minute Exchange of Dies - SMED.

(iv) Visual Management-Andon system implementation.

(v) Takt Time. 
International Journal of Mathematical, Engineering and Management Sciences

Vol. 2, No. 2, 85-109, 2017

https://dx.doi.org/10.33889/IJMEMS.2017.2.2-009

(vi) Kanban.

(vii) $5 \mathrm{~S}$.

(viii) Implementation of cell and flexible production systems.

(ix) Self-inspection (Jidohka, Autonomation).

(x) Error Proofing (Poka Yoke).

Lean tools and methods are successfully integrated in today's Lean Six Sigma implementation practices (Fig. 1), and detailed implementation is available in literature (George, 2002, 2003; Brue, 2000; Mladjenovic, 2003).

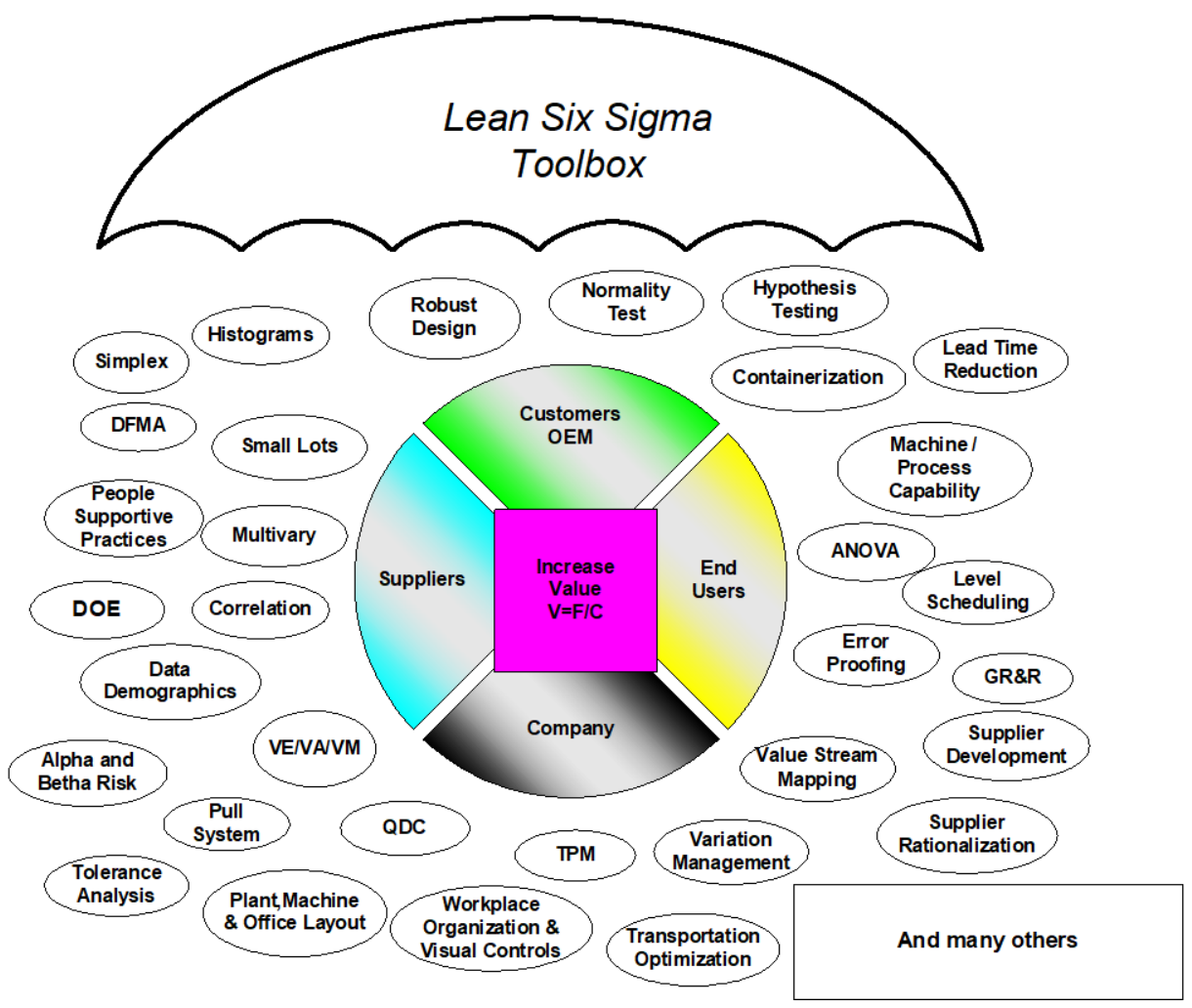

Fig. 1. Lean Six Sigma toolbox-Synergy (Mladjenovic, 2003)

\section{System Approach to the Lean Six Sigma Implementation \\ 4.1 Possible Approaches}

Over the last twenty years, Six Sigma has evolved from its initial focus - defect reduction and achievement of exceptional quality levels - to an innovative approach with a much broader scope and a goal of improving an organization's value creation and retention (Cobb, 2003; Snee, 2003; Adams, 2003; Basu, 2003; Cook, 2005). At the same time, we can observe an emergence of differing implementation approaches, a rise in complexity, and a broadening of implementation scope. Some of the possible approaches could be:

- project focus - within one organization, unit and/or function, within a value stream, or throughout the entire organization,

- transactional or transformational approach, 
International Journal of Mathematical, Engineering and Management Sciences

Vol. 2, No. 2, 85-109, 2017

https://dx.doi.org/10.33889/IJMEMS.2017.2.2-009

- organization-wide implementation vs. localized implementation,

- implementation in all business systems vs. manufacturing only.

Different approaches to Lean Six Sigma are presented in Fig. 2 (Truscott, 2003; Truscott and Truscott, 2003). These diverging approaches are present during implementation and as implementation mature, and as an organization evolve from one predominant approach to another. These four approaches exist simultaneously, and each of them takes a dominant role based on implementation dynamics. Knowledge of the characteristics and advantages of the four identified approaches is critical to implementation strategy framework, which will be based on an organization's culture, continuous improvement maturity, market-and industry-related dynamics, customers' needs and expectations, and many other factors. Organizations need to develop a Lean Six Sigma implementation model that will allow organizational growth and a flexible implementation framework. Implementation success and sustainability will depend on the selection and the development of the LSS initiative architecture, and its implementation effectiveness. The transformation of an organization's initial state may be defined by: current organization continuous improvement maturity, culture, resource capability, industry and market dynamics, current organization's strategic goals, and other factors that may have a significant influence on the selection of an implementation model.

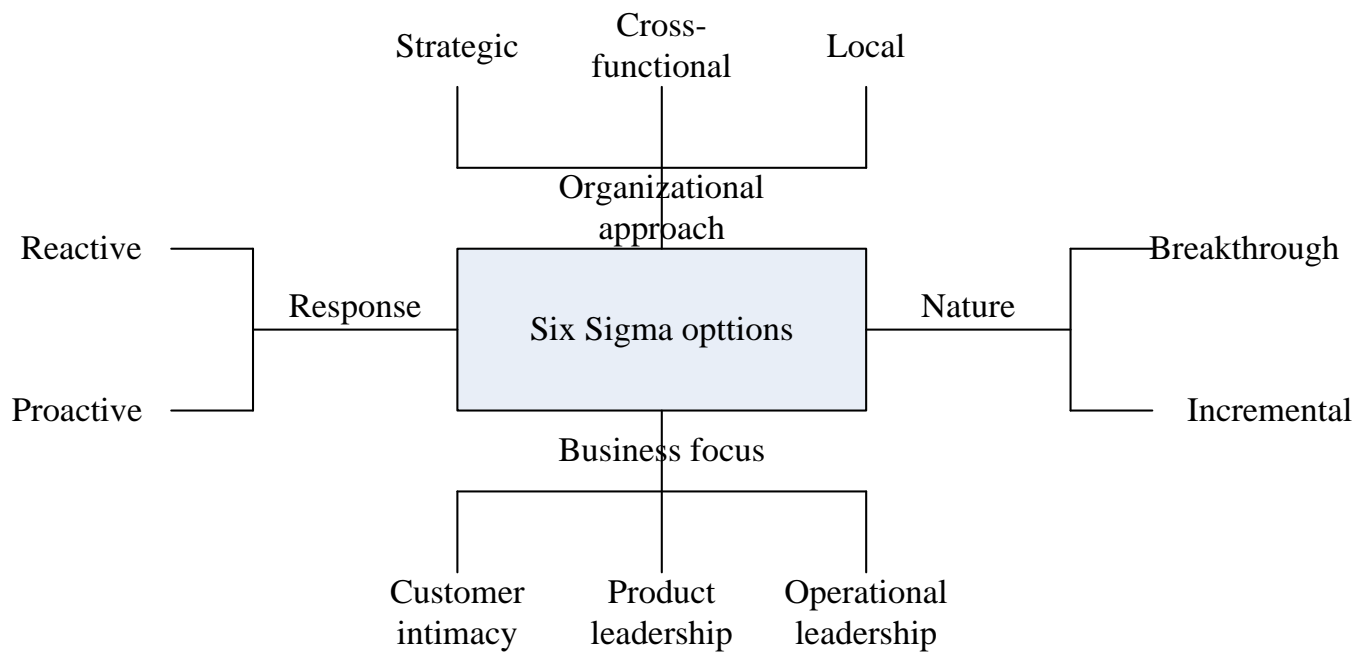

Fig. 2. Lean Six Sigma implementation focus (Truscott, 2003)

Harry (Harry, 2001) indicates that a number of organizations had experienced Lean Six Sigma implementation failure because of a lack of a system approach, inadequate knowledge level required for the development of the implementation framework, and its management. The implementation framework needs to be based on and stay closely connected to the organization's value creation and knowledge management processes. In some aspects, Six Sigma thinking is often in contradiction with prevailing North American management practices. Surveys conducted in the USA indicate that a majority of management is inclined to adopt Crosby's 14 steps (Dushmare, 2001). One of the main reasons for that is that Crosby's approach fits management's preferred choice of a solution that is simple and not technically focused. An organization's cultural and structural diversity and complexity, along with dynamic marketing constraints, 
International Journal of Mathematical, Engineering and Management Sciences

Vol. 2, No. 2, 85-109, 2017

https://dx.doi.org/10.33889/IJMEMS.2017.2.2-009

prevents implementation of an off-the-shelf program that you can just buy and implement without transformational changes that are often significant.

Furthermore, although using the same implementation tools and activities, a unique organization's strategic and associated Lean Six Sigma goals and objectives will result in a distinctive architectural framework, characteristics, and dynamics. The detailed system-based new product and/or strategy development approach was developed by Martin (Martin, 2000) and a system alignment of the business metrics and strategies by Cobb (Cobb, 2003). They are presented in Fig. 3, and 4, respectively.

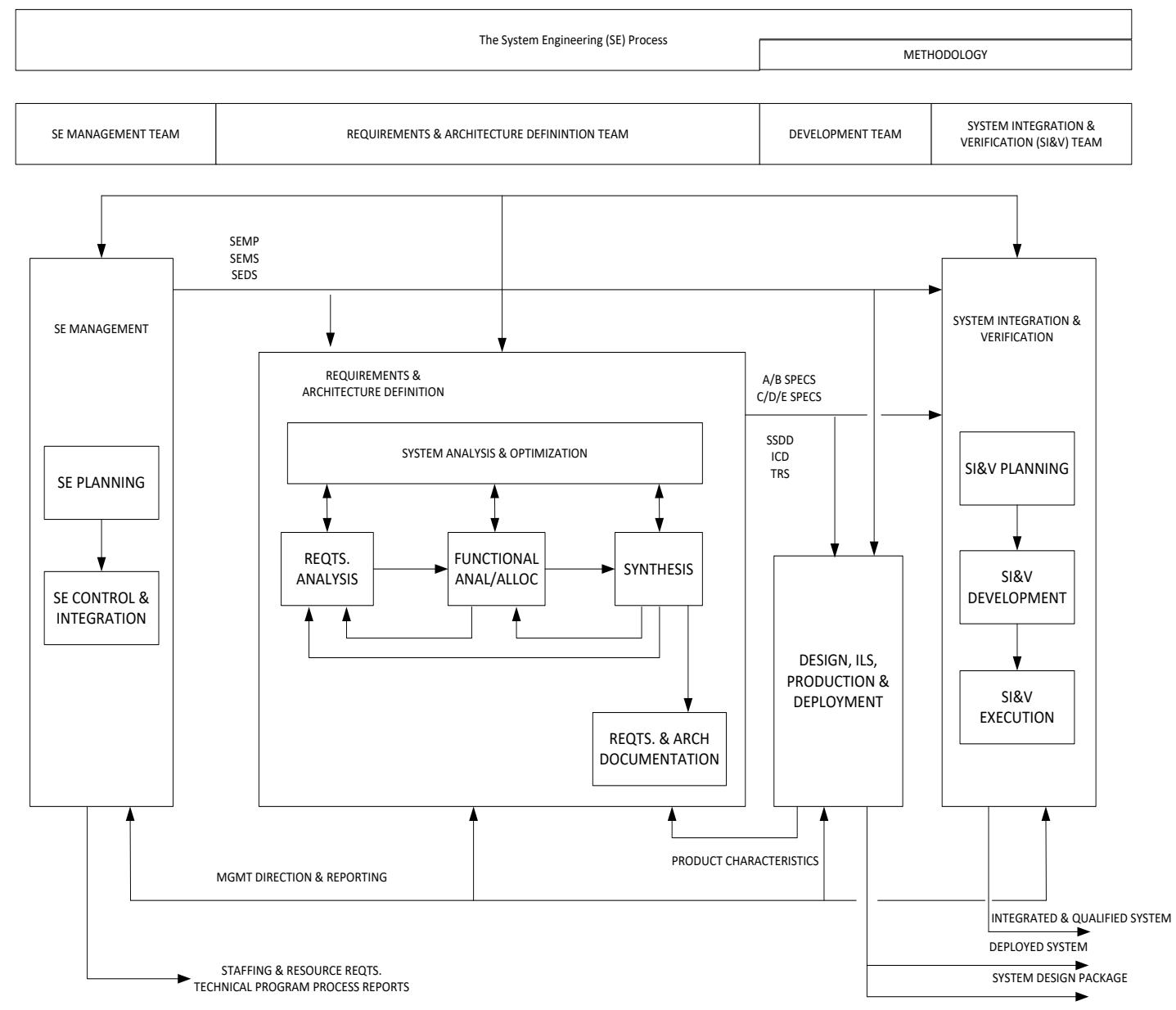

Fig. 3. System-based new product and/or strategy development approach (Martin, 2000)

A significant and shared characteristic of Six Sigma organizations is that they have resources that are competent, capable, and empowered. People in successful Six Sigma organizations clearly understand the organization's purpose and vision. In addition, they are motivated, encouraged, and empowered to continuously learn, and continuously improve processes through their day-today work, experimentation, and knowledge creation and retention. These Six Sigma values are universal and natural principles similar to the values identified by Covey and Truscott (Covey, 1990; Truscott, 2003) - purpose and commitment, capability and learning. 
International Journal of Mathematical, Engineering and Management Sciences

Vol. 2, No. 2, 85-109, 2017

https://dx.doi.org/10.33889/IJMEMS.2017.2.2-009

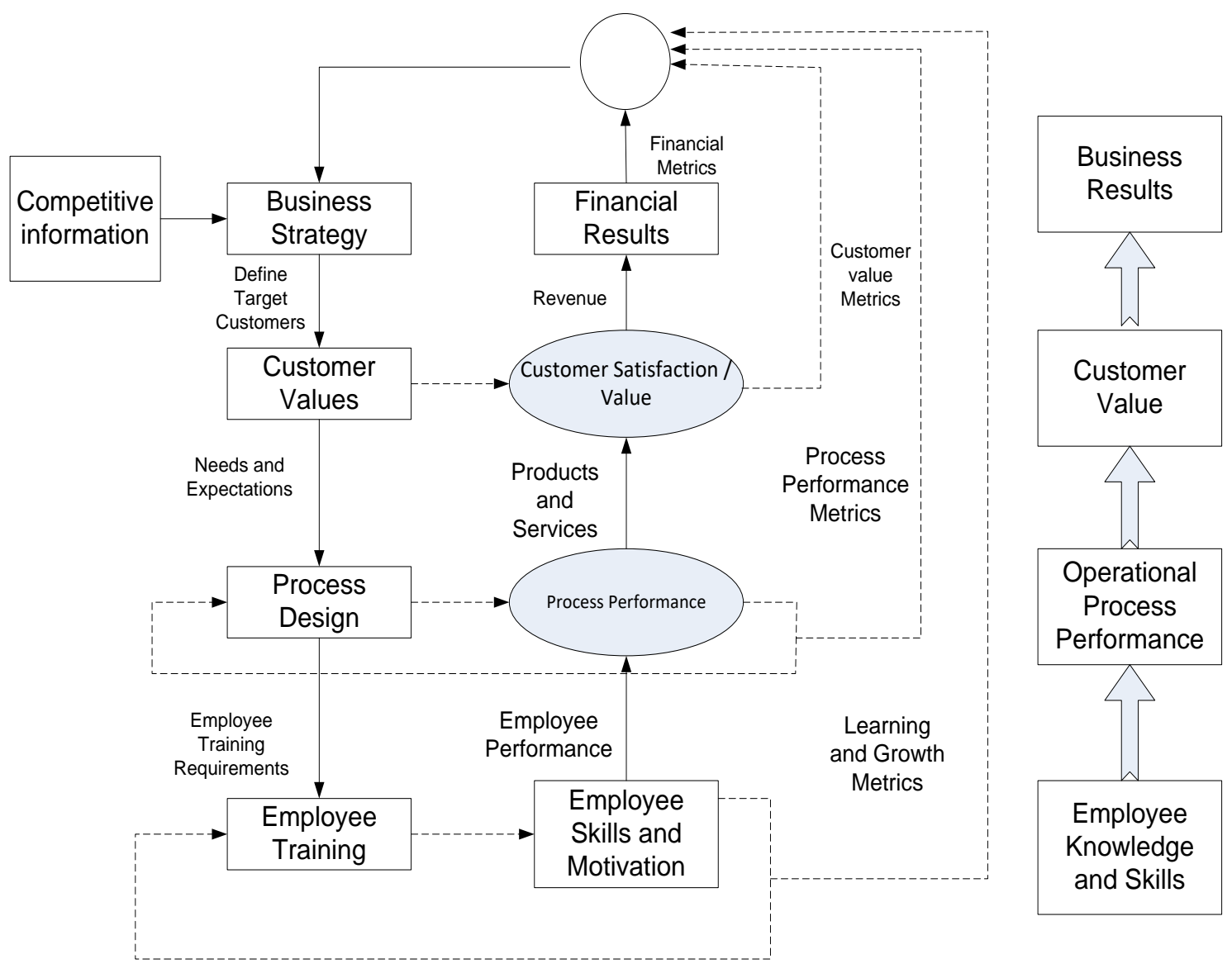

Fig. 4. Business metrics and strategy alignment (Cobb, 2003)

\subsection{Purpose and Commitment}

According to Truscott (Covey, 1990; Truscott 2003) an organization needs to clearly identify a mission and shared vision that should be adopted and integrated into an organization's DNA. To achieve that objective, stakeholders' needs shall be identified, policies that drive decision making adopted, clear organizational objectives set, the and Six Sigma Management System deployed. Management commitment to Six Sigma is an integral part of an organization's overall values. These values are demonstrated daily with management's explicit behaviours that reflect their alignment with an organization's identified, communicated and shared values. It is critical that these values are shared, that all employees are aligned with them, and that decision-making and communication is open and transparent at all levels within an organization. Finally, management commitment is demonstrated by clear identification of the accountability, roles and responsibilities and associated authority related to all aspects of Six Sigma implementation. These activities lead to an organization's transformational change, increased engagement of people, and higher levels of empowerment.

\subsection{Competence, Capability and Capacity}

A successful Six Sigma initiative requires effective management of developing individual competencies, and the capability of an organization's implementation practices and resources 
International Journal of Mathematical, Engineering and Management Sciences

Vol. 2, No. 2, 85-109, 2017

https://dx.doi.org/10.33889/IJMEMS.2017.2.2-009

capacity. Some of the key elements which need to be addressed that can be adopted and applied throughout the organization are:

- detailed training plans,

- careful selection of Black and Green Belts,

- measuring and monitoring of the resource's knowledge and skills and their continual upgrading based on benchmarking,

- ongoing review and assessment of best practices.

Due to Six Sigma implementation organizations experience: increased process and product capability and an overall financial performance improvement. It should be noted that a comprehensive measurement and controlling system is required for monitoring, review, and implementation of required corrective and preventive actions. Once an initial deployment is completed, an organization will realize a need for information systems upgrades and enhancements to allow real time tracking and analysis of key performance metrics. This new capability enables management to quickly make data-driven decisions, and almost immediately implement required actions. Financial and physical resources need to be at a sufficient level to support Six Sigma implementation. Specific focus on these potential constraints is imperative during the initial phase of Six Sigma implementation. Once Six Sigma implementation is mature, the implemented program reduces the need for capital investments, creates high levels of return on investment, and at that implementation point, the risk associated with a lack of adequate levels of financial resources becomes significantly reduced.

\subsection{Learning and Knowledge Management}

In today's knowledge economy, learning and knowledge management are two key drivers of an organization's competitiveness. The purpose of a learning and knowledge management framework is to ensure that continuous improvement processes, including rapid problem--solving, corrective and preventive systems, are implemented and effective. In addition, the organization needs to relentlessly search for new improvement opportunities, and then efficiently implement and track identified actions. Achieved results are normally analyzed for trends, and their impact on overall organizational performance is communicated throughout an organization to allow replication of new knowledge and value creation in all other areas of the organization that may benefit from learnings created during project implementation. The knowledge management process allows for a balance in an organization's knowledge growth and sharing of best practices, tools, and methodologies throughout an organization. It is critical that an adequate framework and "learning self-regulation" support processes are built into a learning and knowledge management system. The purpose of self-regulation structures, which are commonly applied using Plan-DoCheck-Act methodology, is to empower all functions and stakeholders in an organization to identify and prioritize improvement opportunities, carry on improvement actions, and create value and new knowledge. In order to achieve system self-regulation, each of the implementation factors needs to be evaluated on ongoing basis, opportunities for learning identified, and actions required for elevating individual and organizational capability are maintained. In addition to the evaluation and management of the individual elements, there is a need to establish internal and external customer feedback loop that allows for active real-time management of customer satisfaction.

The experience of this author suggests there is no "single optimal implementation solution" for the Six Sigma implementation framework. In today's intensive global economy, innovationdriven market environment, there is a variety of unique organizational characteristics. Despite 
International Journal of Mathematical, Engineering and Management Sciences

Vol. 2, No. 2, 85-109, 2017

https://dx.doi.org/10.33889/IJMEMS.2017.2.2-009

that, there are common characteristics for solutions that are universal. A Six Sigma strategy architecture needs to be developed taking into consideration an organization's unique characteristics - people, processes and technology, while applying universal principles and values.

\section{Identification of Success Factors for Six Sigma Strategy Implementation}

A review of the Six Sigma methodology-related literature reveals a variety of approaches, as well as identification of the success factors. This variety of approaches is driven mainly by specific experiences associated with implementation of the initiative in specific types of organizations, industry sectors, or any other demographic cluster-industry, service vs. manufacturing, scope of objectives and goals, financial vs. transformational, etc. For example, Spanyi and Wurtzel (Spanyi and Wurtzel, 2003) have identified the following Six Sigma implementation success factors:

(i) Visible management commitment.

(ii) Keen sense of urgency.

(iii) Clear definition of customer requirements.

(iv) Shared understanding of core processes and key customers.

(v) Honesty in measuring current performance.

(vi) Discipline in prioritizing the critical few improvement projects.

(vii) Communicating success stories and proving that the approach works.

(viii) Rewarding and recognizing the performers.

(ix) Institutionalizing the approach.

Goldstein (Goldstein, 2001), on the other hand, identifies fourteen Six Sigma program success factors:

(i) Deployment plan.

(ii) Active participation of the senior executives.

(iii) Project reviews.

(iv) Technical support (Master Black Belts).

(v) Full-time vs. part-time resources.

(vi) Training.

(vii) Communications.

(viii) Project selection.

(ix) Project tracking.

(x) Incentive program.

(xi) Safe environment.

(xii) Supplier plan.

(xiii) Customer "WOWs".

(xiv) Implementation planning.

Young (Young, 2001) takes a systemic view, similar to the balance scorecard approach. He identified the adoption into an organization's DNA as the ultimate implementation objective that becomes the key factor influencing organizational success and survival in a global knowledge economy (Fig. 5). 
International Journal of Mathematical, Engineering and Management Sciences

Vol. 2, No. 2, 85-109, 2017

https://dx.doi.org/10.33889/IJMEMS.2017.2.2-009

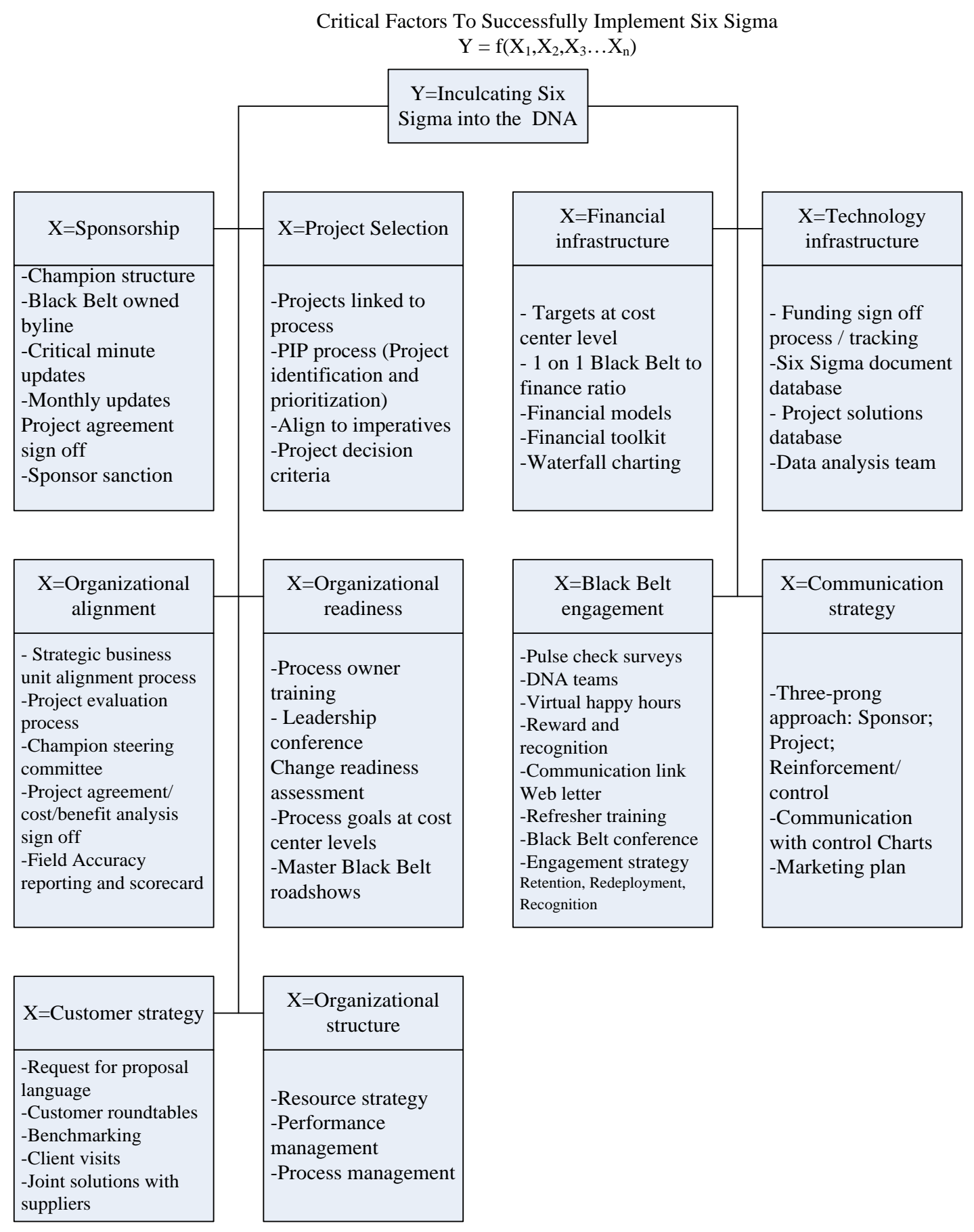

Fig. 5. Six Sigma implementation key success factors (Young, 2001)

Young's critical factors for the successful implementation of Six Sigma are:

(i) Sponsorship.

(ii) Organizational alignment.

(iii) Project selection. 
International Journal of Mathematical, Engineering and Management Sciences

Vol. 2, No. 2, 85-109, 2017

https://dx.doi.org/10.33889/IJMEMS.2017.2.2-009

(iv) Organizational readiness.

(v) Customer strategy.

(vi) Organizational structure.

(vii) Financial infrastructure.

(viii) Technology infrastructure.

(ix) Black Belt engagement.

(x) Communication strategy

Several authors add knowledge management to the list of the key success factors (Harry, 2001; Schmidt, 1999; Brue, 2000).

Some of the authors focus on potential implementation failures and point out that organizations should focus on prevention of these failures. Dushmare conducted several surveys related to Six Sigma implementation (Dushmare, 2001, 2003, 2004). He indicates that the number of organizations which implement Six Sigma is growing, but at the same time, a number of companies are abandoning implementation. Published survey results indicate possible reasons for Six Sigma implementation failure:

(i) Lack of upper management commitment and support.

(ii) Misalignment between selected projects and organization's strategic objectives ${ }^{1}$.

(iii) Management training (inadequate project identification and selection).

(iv) Six Sigma initiative led by middle management, resulting in tactical rather than strategic project selection.

(v) Limited Six Sigma application - only as the tool set for problem solving 2 .

(vi) Lack of continuous learning, sharing lessons learned, and knowledge management ${ }^{3}$.

The majority of the authors agree that successful Six Sigma implementation is directly linked to successful project execution and attainment of associated financial results. These objectives can be realised if projects are carefully chosen, Black and Green Belts are effectively selected and assigned to projects, and the required levels of management commitment and support are reached. These factors are commonly identified as the successful Six Sigma Key Process Input Variables (KPIV).

\section{Identification of Successful Six Sigma Implementation Parameters}

One of the most complex steps during problem solving involves appropriate problem definition, identification of metrics and how data are collected (Harry, 1994, The Vision of Six Sigma: Tools and Methods for Breakthrough Sigma). In addition, an organization's process knowledge maturity will contribute to the "richness and size" of a solutions domain. During the project measure phase, the project team selects metrics, which will define the boundaries of a solution domain, as

${ }^{1}$ It should be noted that presented key sucess factors are interrelated. According to Mikel Harry (Dirk Dushmare, February, 2003) the root cause for the implementation failure is the lack of adequate management training and associated capability.

${ }^{2}$ Harry has identified that: "Leadership contributes $99 \%$ to the Six Sigma implementation sucess". Linsenmann (DuPont Coroprate Champion) has stated that companies that approach Six Sigma implementation as a program for cost reduction will not have sustainable Six Sigma implementation.

${ }^{3}$ Based on survey analysis Dushmare (February, 2003) has concluded that the key reason why Six Sigma implementation fails in the number of organizations is the fact that only $5 \%$ of organizations have implemented knowledge management. 
International Journal of Mathematical, Engineering and Management Sciences

Vol. 2, No. 2, 85-109, 2017

https://dx.doi.org/10.33889/IJMEMS.2017.2.2-009

well as the convergence speed of a solution process. The design and development of an agile measurement system that warrants creation of required levels of information, while using minimal resources, is the goal of this process. The type, volume, and character of the collected data will determine the applied statistical analysis, amount, and value of the created knowledge. Dr. Harry - in his book Vision of Six Sigma: A Roadmap for Breakthrough Sigma, (Harry, 1994) summarized the value of measurement:

- we don't know what we don't know,

- if we can't express what we know in the form of numbers, we really don't know much about it,

- if we don't know much about it, we can't control it,

- if we can't control it, we are at the mercy of chance.

There is a variety of possible project success measures, and a number of different approaches that an organization and/or project team can take when measuring project success. ${ }^{4}$ Some of the possible approaches are:

(i) Financial metrics - savings, ROI, NPV.

(ii) Product and/or process Sigma value (capability).

(iii) Customers' - internal and external - satisfaction.

(iv) The amount of change in a project scope.

(v) Solution sustainability.

(vi) Project cost variance.

(vii) Project delay (time variance).

During our research, we have used the following input and output metrics:

Input metrics:

- selection and characteristics of Black Belts,

- management support,

- project selection and effectiveness of execution.

\section{Output metrics:}

- completion of project on-time,

- project financial goals achievement,

- realization of targeted sigma level.

\section{Empirical Data Statistical Analysis}

\subsection{Sample Selection Methodology}

Research goals and research methodology determine the sample selection approach. When a research goal is focused on getting general results that can be applied to the entire population, a random sample selection is an appropriate approach. On the other hand, if the research goal is to gain knowledge related to a specific application/segment, or in cases when a complete sample

\footnotetext{
${ }^{4}$ It should be noted that the same project may be viewed as sucess or failure. For example if Black Belt sucessfully acheive targeted process capability within project timeline, using appropriate six sigma tools project will be considered sucess from Black Belt perspective. However if the same project does not realize expected financial benefits due to changes in the business enviroment and/or poor improvement financial estimation it will be considered as failure by the Champion.
} 
International Journal of Mathematical, Engineering and Management Sciences

Vol. 2, No. 2, 85-109, 2017

https://dx.doi.org/10.33889/IJMEMS.2017.2.2-009

randomization would not be practical, selection of the samples will not be completely randomized. In our research, we have used samples that were not completely randomized since our research goal was to establish significance of a relationship between selected factors that we have hypothesized are significant for successful Six Sigma implementation. Totally randomized sample selection was not practical, since data representing the selected group of Black Belts was from one global corporation belonging to one industry segment - the automotive industry, and not a broader population. In the case of non-probabilistic samples, there is no expectation that each sample will have the same chance to be selected. Instead of the totally randomized sampling, two alternative techniques may be employed: the first one is quota sampling, and the second is purposeful sampling, the latter of which includes convenience sampling (Box et al., 1978; Montgomery, 2001). The convenience sampling uses individual samples based on their sequence, and this approach creates maximal levels of information for the particular problem under investigation. The focus of this method is on the specific rather than on general problems, and based on that it always reduces time, money, and effort spent on research. A research goal, resources, and time constraints determine the applied research technique and sample size. Samples that were used for this research work were selected from the Six Sigma database. In this particular situation, global Six Sigma implementation was done in three geographical areas: North America, England, and Central Europe. These deployments had different implementation start times so we had to ensure that normalization of the samples was done in order to minimize the influence of implementation "maturity".

\subsection{Research Design}

A common research design goal is a high level of effectiveness with interactions of the independent factors. The selection of the research plan was based on the research team's knowledge of the sources of variability within the examined system, and the statistical design of experiments was selected with a goal of effective procedure. In this particular case, the factorial design plan was selected to be as adequate to determine the effects of independent variables on the system output response (Montgomery, 2001). Factorial design of the experiment plan provides answers related to the independence of the factors. In addition, it allows for effort conservation, since each of the main effects can be determined with the same level of precision as would be the case if the whole experiment was dedicated to analysis of that single factor (Cochran, 1977).

We have used factorial design of experiments, which utilize MANOVA, ANOVA and the t-test approach, because of their flexibility, simplicity, high-level effectiveness, and capability to estimate the interactions of the independent variables. The design of the experiment matrix consists of six independent variables provided in Table 2.

Dependant variables that were investigated were:

- project completion on time: Z,

- project financial results: F,

- achieved target Sigma value: S,

- overall success: U. 
International Journal of Mathematical, Engineering and Management Sciences

Vol. 2, No. 2, 85-109, 2017

https://dx.doi.org/10.33889/IJMEMS.2017.2.2-009

\begin{tabular}{|c|c|c|c|c|c|c|}
\hline & \multicolumn{6}{|l|}{ Factors } \\
\hline & $\begin{array}{l}\text { BB Competence } \\
\text { level (CPT) }\end{array}$ & $\begin{array}{l}\text { Project Type } \\
\text { (TP) }\end{array}$ & $\begin{array}{l}\text { Project } \\
\text { complexity } \\
\text { (KOM) } \\
\end{array}$ & $\begin{array}{l}\text { Project } \\
\text { selection } \\
\text { (IP) } \\
\end{array}$ & $\begin{array}{l}\text { Management } \\
\text { Support (PM) } \\
\end{array}$ & $\begin{array}{l}\text { Project } \\
\text { duration } \\
\text { (TRA) } \\
\end{array}$ \\
\hline \multirow[t]{2}{*}{ Levels } & $\mathrm{Hi}$ & Service & $\mathrm{Hi}$ & $\mathrm{Hi}$ & \multirow{2}{*}{ Variable } & \multirow{2}{*}{ Variable } \\
\hline & Low & Manufacturing & Low & Low & & \\
\hline
\end{tabular}

Table 2. Matrix: levels of input factors

Since all independent variables were normalized, we have introduced the overall success independent variable, which was calculated:

$U=\sqrt[3]{Z \times F \times S}$

Dependant variables that were analysed together in a multivariate analysis of variance using MANOVA and ANOVA analysis were:

- finishing project on time: relative value of project duration in relation to planned duration,

- achieved financial benefits: value of achieved financial results relative to planned financial results,

- achieved sigma level: value of actual achieved sigma value, relative to project goal sigma value.

The observation data from the database were clustered according to required levels of the independent variables, and then samples were randomly selected.

\subsection{Data Analysis}

Statistical analysis was performed using Minitab software. The first step of the analysis included preparation and organization of the data, which was completed in the following way:

- Data was normalized relative to time, utilizing the selection of the samples resulting from the same sequential position during implementation (the same wave of the Black Belt training),

- project completion was normalized relative to planned completion time,

- achieved financial results were represented relative to the planned financial results,

- normalized attained Sigma value was calculated as the relative percentage of the planned sigma value.

Percentage deviations for each of the projects were calculated using Microsoft Excel software.

During the research, we have used multivariate analysis of variance (MANOVA), analysis of variance for models, and two sample t-tests. Multivariate analysis of variance (MANOVA) is simply an ANOVA with several dependent variables. That is to say, ANOVA tests for the difference in means between two or more groups, while MANOVA tests for the difference in two or more vectors of means. 
International Journal of Mathematical, Engineering and Management Sciences

Vol. 2, No. 2, 85-109, 2017

https://dx.doi.org/10.33889/IJMEMS.2017.2.2-009

This procedure has a couple of advantages compared to ANOVA methodology. The first advantage is that when we test multiple variables, there is higher likelihood of identifying which of the factors are significant. In addition, this methodology provides better protection against "Type 1" errors, which may occur if we conduct a multiple independent ANOVA test.

The MANOVA procedure can discover differences that are in most cases hidden during ANOVA testing. The MANOVA methodology assumes that dependant variables are normally distributed, and that variances are homogenous. Similar to ANOVA, MANOVA method can be applied with samples that are not equal.

The ANOVA procedure calculates total variability, and then identifies and recognizes which of the sources of variability has a significant effect. Some possible sources of variability include a difference in levels of treatments, differences in the classes, residual variances, and experimental error. ANOVA is similar to regression in that it can be applied to determine and model relationships between one dependant and one or multiple independent variables. At the same time, there are certain differences; specifically, that independent variables can be qualitative (attribute) and quantitative (continuous / discrete variables). In essence, ANOVA broadens the scope of the two-sample t-test of the means, to the hypothesis testing that that at least one of the multiple averages is different.

During our research, multivariate analysis of variance (MANOVA) was conducted on dependent variables with the objective of performing a simultaneous test of equal means relative to independent variables. GLM (General Linear Method) is an ANOVA procedure with balanced data. GLM can be seen as expanded linear multiple regression for one dependant variable. One of the main purposes of multiple regression is to quantify the relationship between independent or predetermined variables. In addition, GLM allows linear transformation or linear combination for multiple dependant variables. This characteristic expands GLM procedure and creates its advantage relative to multiple regression that can be applied for one dependent variable.

A multivariable significance test for linear combination of the multiple dependant variables provides a view into dimensions of the dependant variables, which are related to independent variables. An additional advantage is its ability to analyze the effect of the repeated factor measurements. Experimental plans with repeated measurements are utilized traditionally in ANOVA. In order to analyze repeated measurements in GLM, a linear responses combination that describe the effect of the repeated measurements - for example responses under different conditions - can be designed and tested for significance using variable or multivariable approaches.

The MANOVA procedure was performed using the Lawley-Hotelling Trace test for every element of the model and for specific conditions. Statistical analysis has employed Hotelling Trace coefficient. T2 test statistics was calculated using equation 2 :

$T 2=(N-2) U$

Procedure steps:

Step 1: Parameter Estimation. Estimates that were presented include parameter estimation, standard error estimation, t-values, and their associated $\mathrm{p}$ values. Standard errors represent measuring errors, and large errors indicate poor estimation. The method's relationship 
International Journal of Mathematical, Engineering and Management Sciences

Vol. 2, No. 2, 85-109, 2017

https://dx.doi.org/10.33889/IJMEMS.2017.2.2-009

significance was determined using $t$ values, where the $t$ values were calculated dividing average by standard errors. Preferred $t$ value for determination of significance between independent input variables and response is $\alpha=0,05$. Based on that, an application of the significance level $\alpha=0,05$ has a result that significant factors are determined as factors with associated $\mathrm{p}$ values that are less than $0,05(\mathrm{p}<0,05)$.

Step 2: Model-Testing Procedures. The purpose of model testing procedures is to determine the relationship between independent variables - Black Belt competence (CPT), project type (TP), project complexity (KOM), project selection (IP), management support (PM) and project duration (TRA) and the continuous improvement implementation results achieved determined by dependant variables - Project on - time completion (ZAV), financial benefits acheived (FIN), targeted Sigma values acheived (S) and overall project success (U) as per Table 3. To test this hypothesis we have used the MANOVA method and Minitab software solver.The significance of the independent and dependent variables relationship was determined using MANOVA. We should note that data were not balanced and that has led to the use of GLM - MANOVA.

\begin{tabular}{|c|c|c|c|c|c|}
\hline \multicolumn{6}{|c|}{ Independent variables } \\
\hline $\begin{array}{c}\text { Black Belt } \\
\text { competence CPT }\end{array}$ & Project type TP & $\begin{array}{c}\text { Project complexity } \\
\text { KOM } \\
\end{array}$ & $\begin{array}{c}\text { Project selection } \\
\text { IP } \\
\end{array}$ & PM & $\begin{array}{c}\text { Project } \\
\text { duration TRA } \\
\end{array}$ \\
\hline $\mathrm{Hi}$ & Transactional & $\mathrm{Hi}$ & $\mathrm{Hi}$ & \multirow{2}{*}{ Variable } & \multirow{2}{*}{ Variable } \\
\hline Low & Production & Low & Low & & \\
\hline \multicolumn{6}{|c|}{ Dependent variables } \\
\hline $\begin{array}{c}\text { Project on time } \\
\text { completion }\end{array}$ & $\begin{array}{l}\text { Achieved financial } \\
\text { benefits }\end{array}$ & $\begin{array}{l}\text { Achieved targeted } \\
\text { Sigma values }\end{array}$ & $\begin{array}{l}\text { Overall project } \\
\text { success }\end{array}$ & & \\
\hline ZAV & FIN & PPM & Total & & \\
\hline
\end{tabular}

Table 3. Input output factors matrix

Step 3: The t-Test Used for Testing Independent Variables. The values for the Hotelling- T were used for testing the effect of independent variables, since all three independent variables consist of the two levels. This analysis was used to test a null hypothesis--there is no difference in the influence of the average values of the independent variables on dependant variables. Since the experimental plan was not balanced, the General Linear Model (GLM) was used to test the effect of the independent variables on dependant variables, and the t-test was used for testing each of the independent variables on dependant variables. The two-sample t-test was used for hypothesis testing, since we have assumed that standard deviations are not equal. The two-sample t-test with pooled variances was not used since severe errors may occurs if sample variances do not meet equivalence condition.

Step 4: Bartlett Test for Equal Variances Testing. We have used Bartlett's and Levine's tests to determine if variances across samples are equal-homogeneity of variances. Many of the statistical procedures, including ANOVA, assume variance homogeneity, although samples may be selected from the populations with different average values. The effect of the unequal variances on the quality of statistical conclusions will be influenced if the model includes: fixed or random effects, sample size, and selection of a statistical procedure for multiple comparisons. If the model is based only on random factors and sample sizes for the groups are equal or approximately equal, then even if variances are not equal the influence of the t-test on ANOVA is relatively small. Since we had only two levels in the research, we have used the t-test as approximation of the Barlet's test. 
International Journal of Mathematical, Engineering and Management Sciences

Vol. 2, No. 2, 85-109, 2017

https://dx.doi.org/10.33889/IJMEMS.2017.2.2-009

\section{Analysis and Results}

MANOVA was conducted using Minitab 15 software. The Minitab input screen is presented in Fig. 6. Categorical factors CPT, TP, KOM and IP were selected as inputs for a multivariable system response (PPM, FIN, ZAV and Total) model that includes all interactions. The results of Wilson, Lawley-Hotellingovog, Pillaijev and Roy were presented by Mladjenovic (Mladjenovic, 2005). The $p$-values and significance of the factors based on a significance level of $\alpha=0,05$ are presented in Table 4.

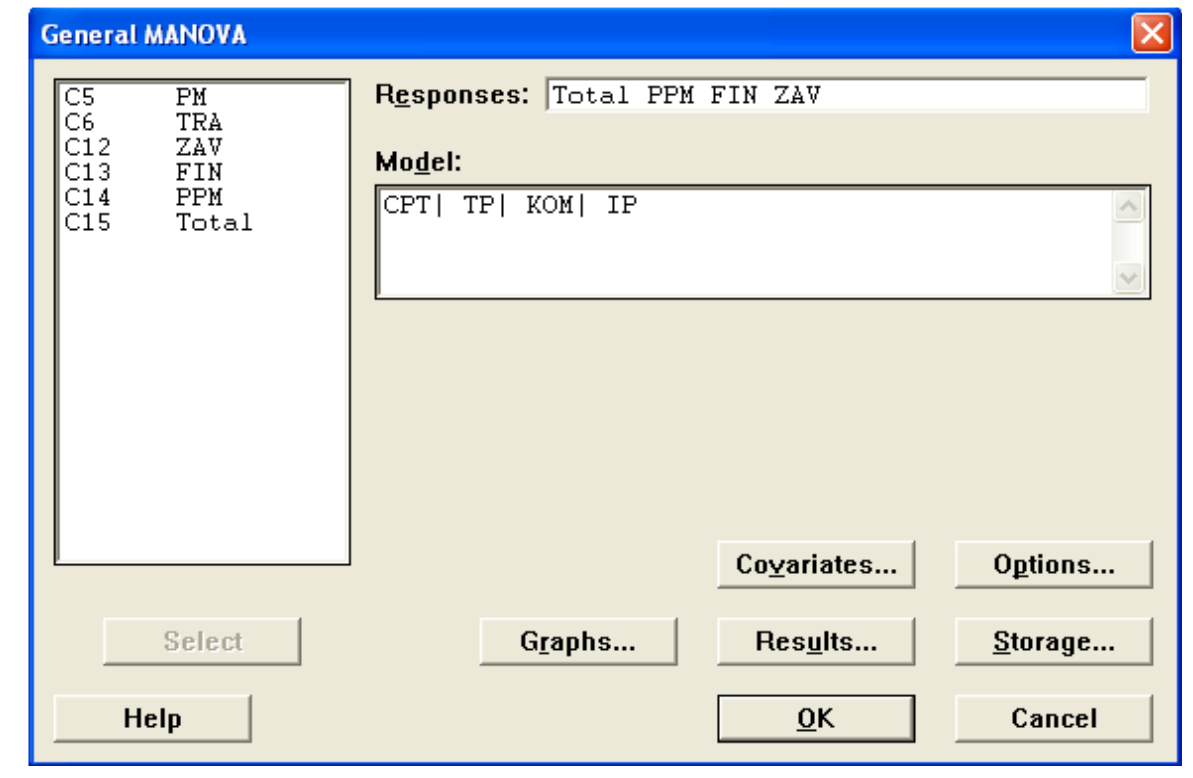

Fig. 6. Software Minitab MANOVA input screen

Next, we have developed a GLM (general linear model) for dependant variables: project--on time completion (ZAV), financial benefits achieved (FIN), targeted Sigma values achieved (S) and overall project success (U). The output screen for the MANOVA analysis using Minitab software is presented in Fig. 6. Categorical input factors: CPT, TP, KOM and IP, and variable input factors (covariate) PM and TRA were used for the development of the system response model (PPM, FIN, ZAV and Total) that included main factors and interaction. In addition, we have performed an analysis of standardized variance residuals, variance analysis, and determined covariate coefficients, and variable coefficients. Detailed results of this analysis are published by Mladjenovic (Mladjenovic, 2005).

\section{ZAV Model:}

$\mathrm{ZAV}=0,014237+0,373326 \mathrm{CPT}$ (Low)-0,091912TP(Production)$0,141174 \mathrm{KOM}($ Low $)+0,114686 \mathrm{IP}($ Low $)-0,29155 \mathrm{PM}+0,08130 \mathrm{TRA}^{5}$ $0,038626 \mathrm{CPT}($ Low $) * \mathrm{KOM}($ Low $)+0,014249 \mathrm{CPT}($ Low $) * \operatorname{IP}($ Low $)+0,, 16768 \mathrm{PM}{ }^{*} \mathrm{CPT}(\mathrm{Low}) 0,0471$ $1 \mathrm{TRA} * \mathrm{CPT}($ Low $) 0,011230 \mathrm{KOM}($ Low $) * \operatorname{IP}($ Low $) 0,21778 \mathrm{PM} * \mathrm{IP}($ Low $) 0,028455 \mathrm{CPT}(\mathrm{Low}) * \mathrm{KO}$ $\mathrm{M}($ Low $) * \operatorname{IP}($ Low $) 0,006961 \mathrm{TP}($ Production)*KOM(Low)*IP(Low)0,6492TRA*PM*IP(Low)0,05 518PM*CPT(Low)*TP(Production)*KOM(Low)+0,7761TRA*PM*CPT(Low)*IP(Low).

The ZAV model had R2 $=89,44 \%$ and $\mathrm{R} 2$ adj $=89,26 \%$.

\footnotetext{
${ }^{5}$ TRA $p$ value is $\mathrm{p}=0,10$, which is borderline $\mathrm{p}$ value.
} 
International Journal of Mathematical, Engineering and Management Sciences

Vol. 2, No. 2, 85-109, 2017

https://dx.doi.org/10.33889/IJMEMS.2017.2.2-009

From the ZAV Main effects plot (Fig. 7) we can observe that CPT had the most significant influence on the projects duration. In addition, projects related to production were completed faster than transactional projects. Project complexity KOM increase results in increased project duration. Increased projects' selection quality IP will result in a reduction of the relative project duration.

The Interaction plot for ZAV is presented in Fig. 8.

\begin{tabular}{|l|l|l|}
\hline Factor & $\mathrm{p}$ & Significant \\
\hline \hline PM & 0,000 & Yes \\
\hline TRA & 0,073 & No \\
\hline CPT & 0,000 & Yes \\
\hline TP & 0,000 & Yes \\
\hline KOM & 0,000 & Yes \\
\hline IP & 0,000 & Yes \\
\hline CPR*TP & 0,612 & No \\
\hline CPT*KOM & 0,000 & Yes \\
\hline CPT*IP & 0,000 & Yes \\
\hline TP*KOM & 0,276 & No \\
\hline TP*IP & 0,036 & Yes \\
\hline KOM*IP & 0,000 & Yes \\
\hline CPT*TP*KOM & 0,008 & Yes \\
\hline CPT*TP*IP & 0,011 & Yes \\
\hline CPT*KOM*IP & 0,000 & Yes \\
\hline TP*KOM*IP & 0,009 & Yes \\
\hline CPT*TP*KOM*IP & 0,002 & Yes \\
\hline
\end{tabular}

Table 4. MANOVA $p$ values $(\alpha=0.05$ significant factors criteria $\mathrm{p}<0.05)$

\section{FIN Model:}

FIN=-0,155351-0,157541CPT(Low)-0,018139TP(Production)- 0,123174KOM(Low)0,195764IP(Low)+0,50212PM-0,10899TRA-

0,007743CPT(Low)*IP(Low)0,13715PM*CPT(Low)+0,07342PM*IP(Low)-

$0,028970 \mathrm{CPT}($ Low $) * \mathrm{KOM}($ Low $) * \operatorname{IP}($ Low $)+0,07338 \mathrm{PM}^{*}$

CPT(Low)*KOM(Low)+0,009606TP(Production)*KOM(Low)*

IP(Low)+0,8617TRA*PM*IP(Low)+0,10578PM*CPT(Low)* TP(Production)*KOM(Low)-

0,07806TRA*CPT(Low)*KOM(Low)*IP(Low)-0,7182TRA*PM*KOM(Low)*IP(Low).

Model R2 $=88,19 \%$ and $\mathrm{R} 2$ adj $=87,60 \%$.

The FIN Main effects plot is presented in Fig. 9. We can see that CPT, KOM and IP have the most significant impact on the increase of projects' financial results FIN. Increased project complexity KOM has a negative impact on the financial results achieved.

Project type TP, PMD and TRAD have a lower influence on the project financial results. The Interaction plot for FIN is presented in Fig. 10. 
International Journal of Mathematical, Engineering and Management Sciences

Vol. 2, No. 2, 85-109, 2017

https://dx.doi.org/10.33889/IJMEMS.2017.2.2-009

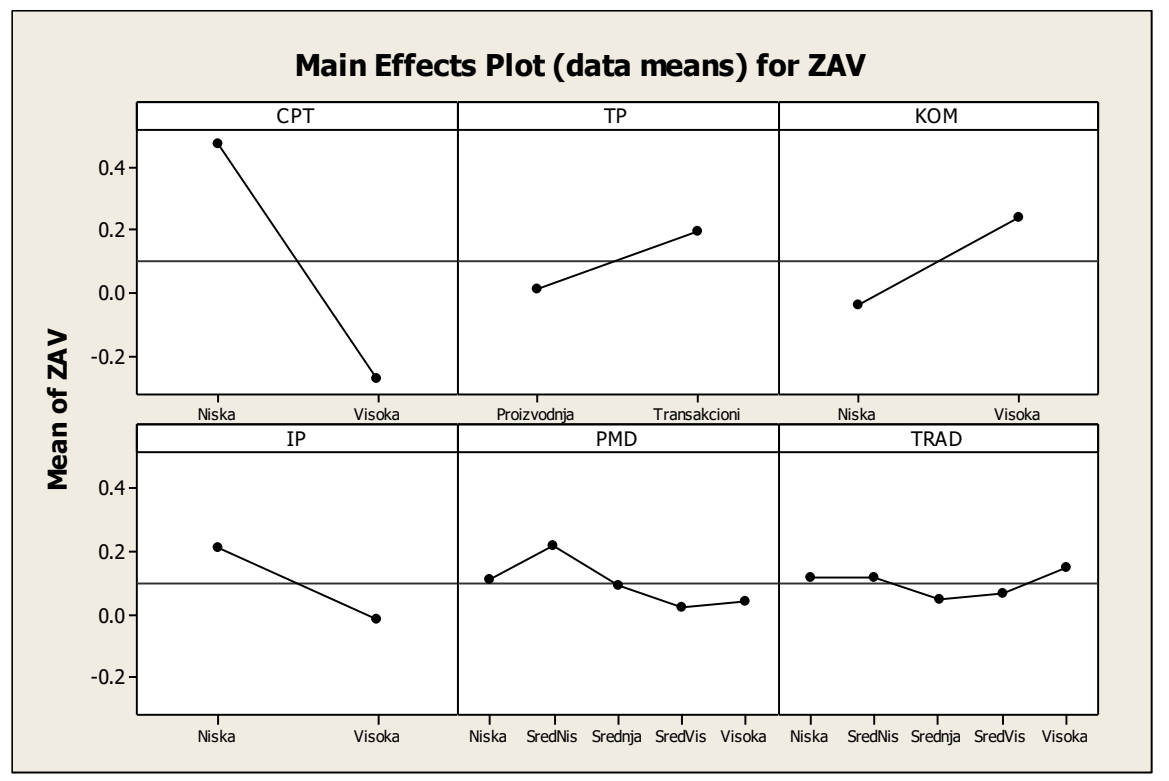

Fig. 7. Main effects plot for ZAV

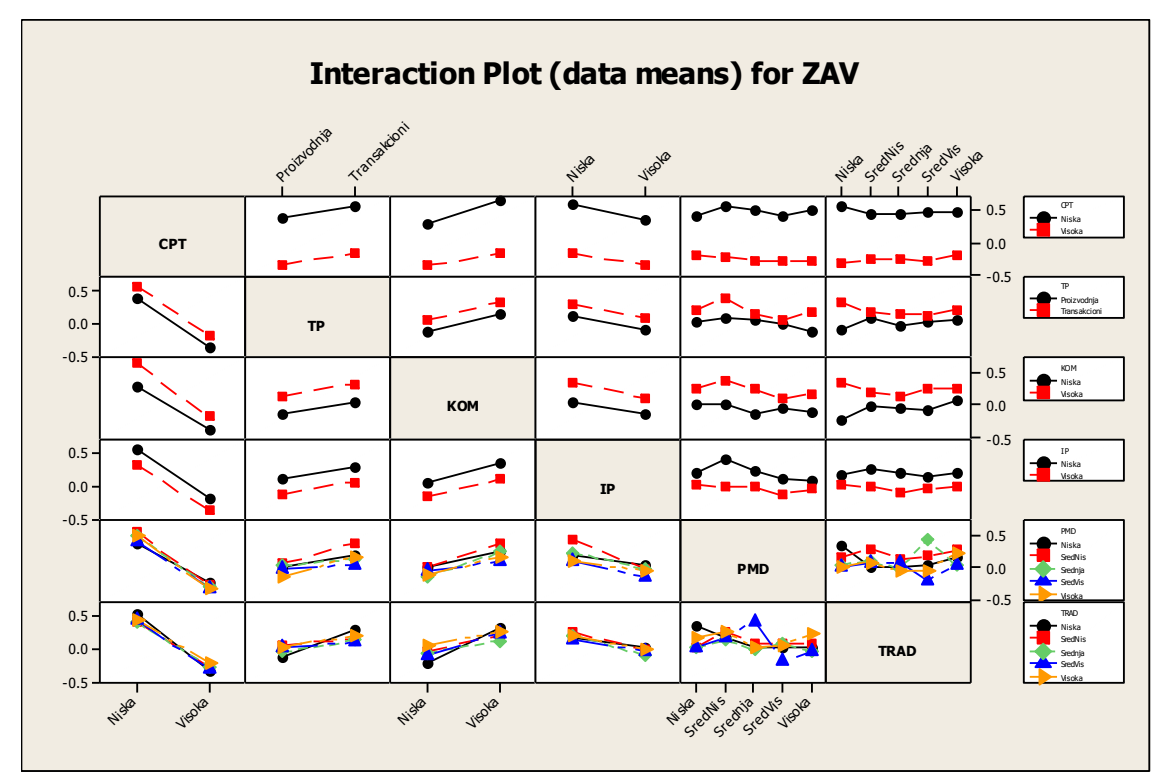

Fig. 8. Interactions - ZAV (project completion) 
International Journal of Mathematical, Engineering and Management Sciences

Vol. 2, No. 2, 85-109, 2017

https://dx.doi.org/10.33889/IJMEMS.2017.2.2-009

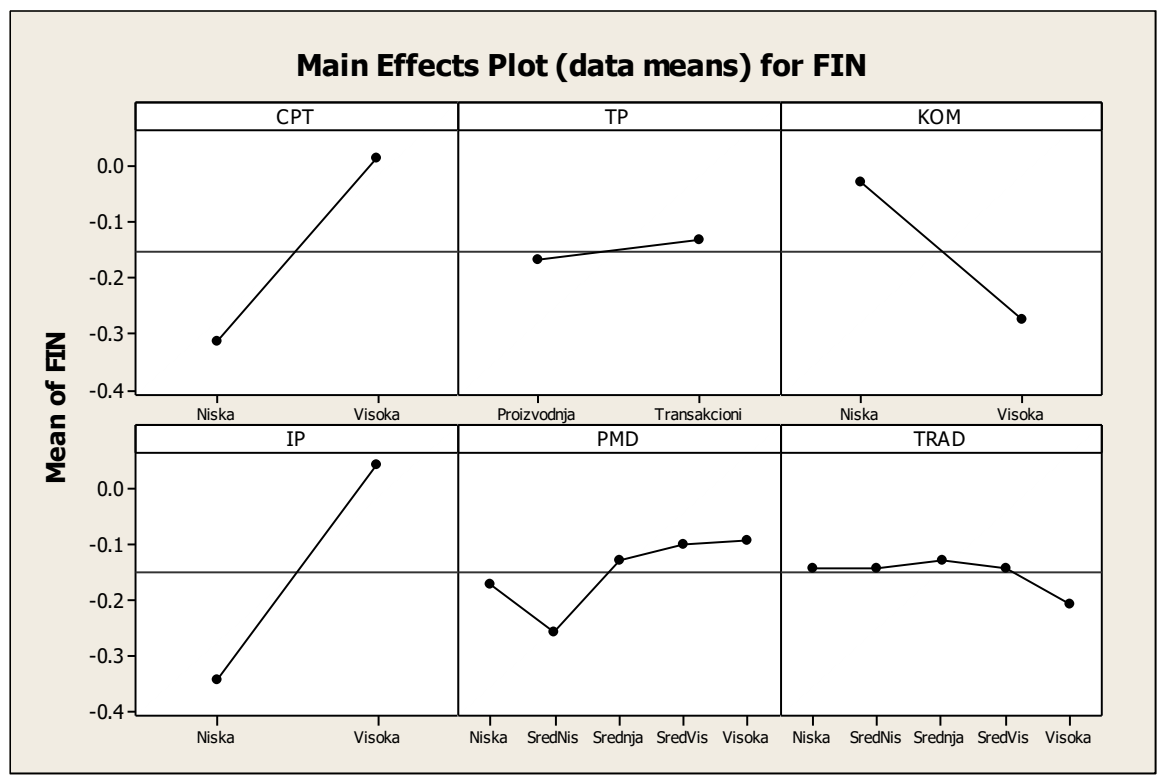

Fig. 9. FIN main effect plot

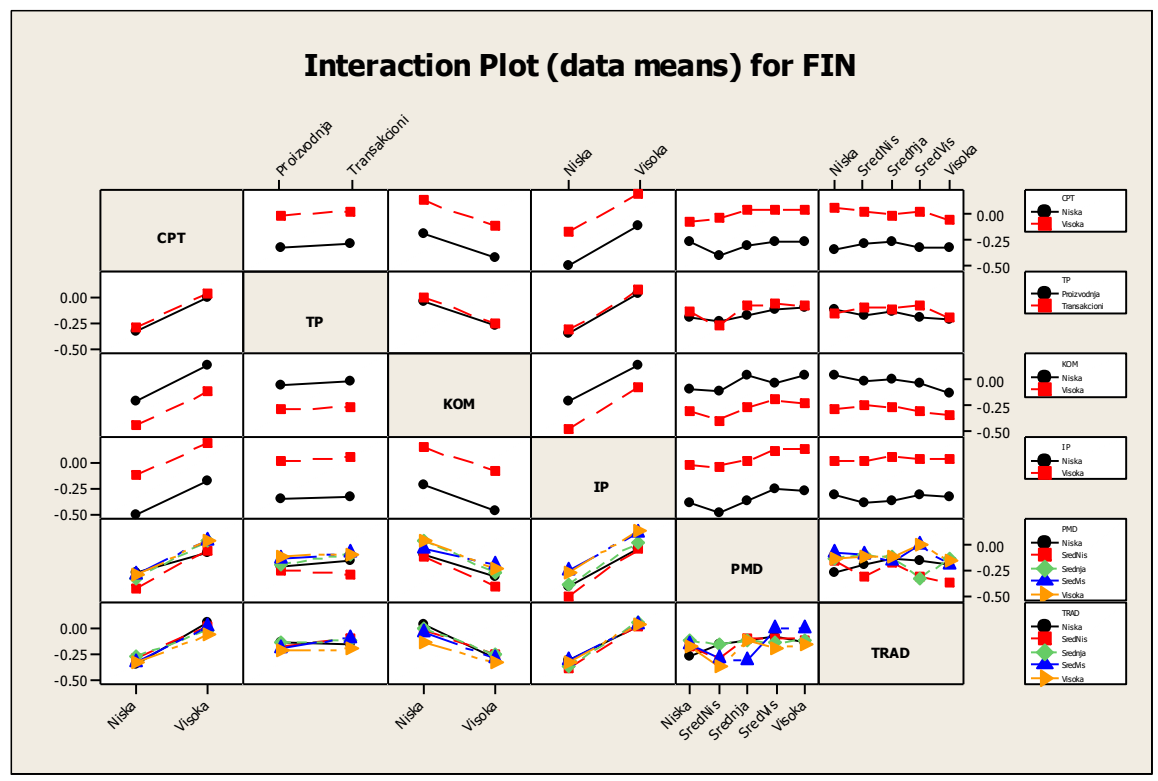

Fig. 10. Interaction plot for FIN

\section{PPM Model:}

$\mathrm{PPM}=0,224830+0,320723 \mathrm{CPT}(\mathrm{Low})+0,006606 \mathrm{TP}$ (Production)0,052570KOM(Low)+0,072884IP(Low)-0,05754PM-0,038421

CPT(Low)*KOM(Low)+0,015694CPT(Low)*IP(Low)+0,18900PM*CPT(Low)+0,023216KOM (Low)*IP(Low)-0,20244PM*IP(Low) +0,022760CPT(Low)*KOM(Low)*IP(Low)$0,04803 \mathrm{PM} * \mathrm{CPT}(\mathrm{Low}) * \mathrm{KOM}(\mathrm{Low}) * \mathrm{IP}($ Low $)-0,4637 \mathrm{TRA} * \mathrm{PM}{ }^{* \mathrm{CPT}}(\mathrm{Low}) * \mathrm{KOM}(\mathrm{Low}) *$ IP(Low). 
International Journal of Mathematical, Engineering and Management Sciences

Vol. 2, No. 2, 85-109, 2017

https://dx.doi.org/10.33889/IJMEMS.2017.2.2-009

PPM model $: \mathrm{R} 2=89,38 \%$ i R2 adj $=89,19 \%$.

The Main effects plot for PPM with discrete PM and TRA values is presented in Fig. 11. From the PPM Main plot effect graph, we can conclude that CPT has the most significant influence on defect reduction PPM (sigma level).

Project type TP, PMD I TRAD do not have a high impact on reduction of the PPM. In addition, right project selection IP, and project complexity KOM have respectively less significant positive and negative influence.

The Interaction plot for FIN is presented in Fig. 12.

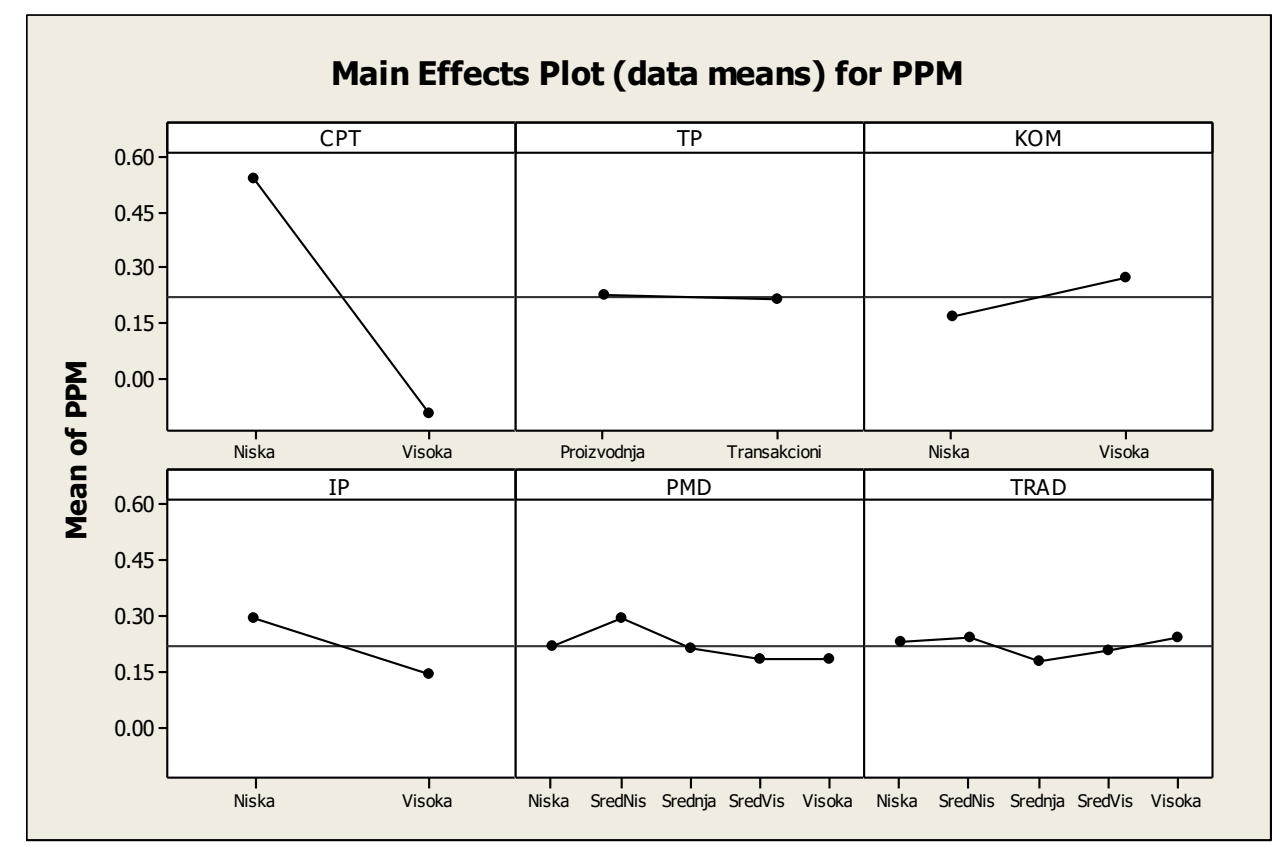

Fig. 11. PPM main effect plot

\section{Total Model:}

Total=-0,137046-0,240940CPT(Low)+0,125505KOM(Low)0,146464IP(Low)+0,27202PM+0,052174CPT(Low)*KOM(Low)$0,053989 \mathrm{CPT}($ Low $) * \operatorname{IP}($ Low $)+0,014104 \mathrm{TP}($ Low $) * \operatorname{IP}($ Low $)-0,036221$

$\mathrm{KOM}(\mathrm{Low}) * \mathrm{P}($ Low $)+0,12838 \mathrm{PM} * \mathrm{KOM}($ Low $)-0,12120 \mathrm{PM} * \mathrm{IP}($ Low $)-$ $0,009803 \mathrm{CPT}($ Low $) * \mathrm{TP}($ Production)*KOM(Low)+0,008022

CPT(Low)TP(Production)*IP(Low)+0,11447PM*CPT(Low)*TP(Production)$0,037655 \mathrm{CPT}($ Low $) * \mathrm{KOM}($ Low $) * \mathrm{IP}($ Low $)+0,07234$

PM*CPT(Low)*KOM(Low)+0,08777TRA*CPT(Low)*KOM(Low)0,10493 RRA $^{*}$ CPT(Low)*IP(Low) $+0,013077 \mathrm{TP}$ (Production)* $\mathrm{KOM}($ Low $) * \mathrm{IP}($ Low $)+0,07221 \mathrm{PM} * \mathrm{TP}($ Production $) * \mathrm{KOM}($ Low $)-$ $0,16231 \mathrm{PM} * \mathrm{TP}($ Production)*IP(Low)+0,010297CPT(Low)* TP(Production)*KOM(Low)*IP(Low)+0,11778PM*CPT(Low)* TP(Production)* IP(Low)$0,19470 \mathrm{PM}{ }^{*} \mathrm{CPT}(\mathrm{Low}) * \mathrm{KOM}(\mathrm{Low}) * \mathrm{IP}(\mathrm{Low})+$ 0,08919PM*TP(Production)*KOM(Low)*IP(Low)-0,13171 
International Journal of Mathematical, Engineering and Management Sciences

Vol. 2, No. 2, 85-109, 2017

https://dx.doi.org/10.33889/IJMEMS.2017.2.2-009

PM*CPT(Low)*TP(Production)*KOM(Low)*IP(Low)+1,1448TRA*

PM*TP(Production)*KOM(Low)*IP(Low)-1,0328TRA*PM*

CPT(Low)*TP(Production)* KOM(Low)*IP(Low).

PPM model R2 $=88.39 \%$ and $\mathrm{R} 2 \mathrm{adj}=87.86 \%$.

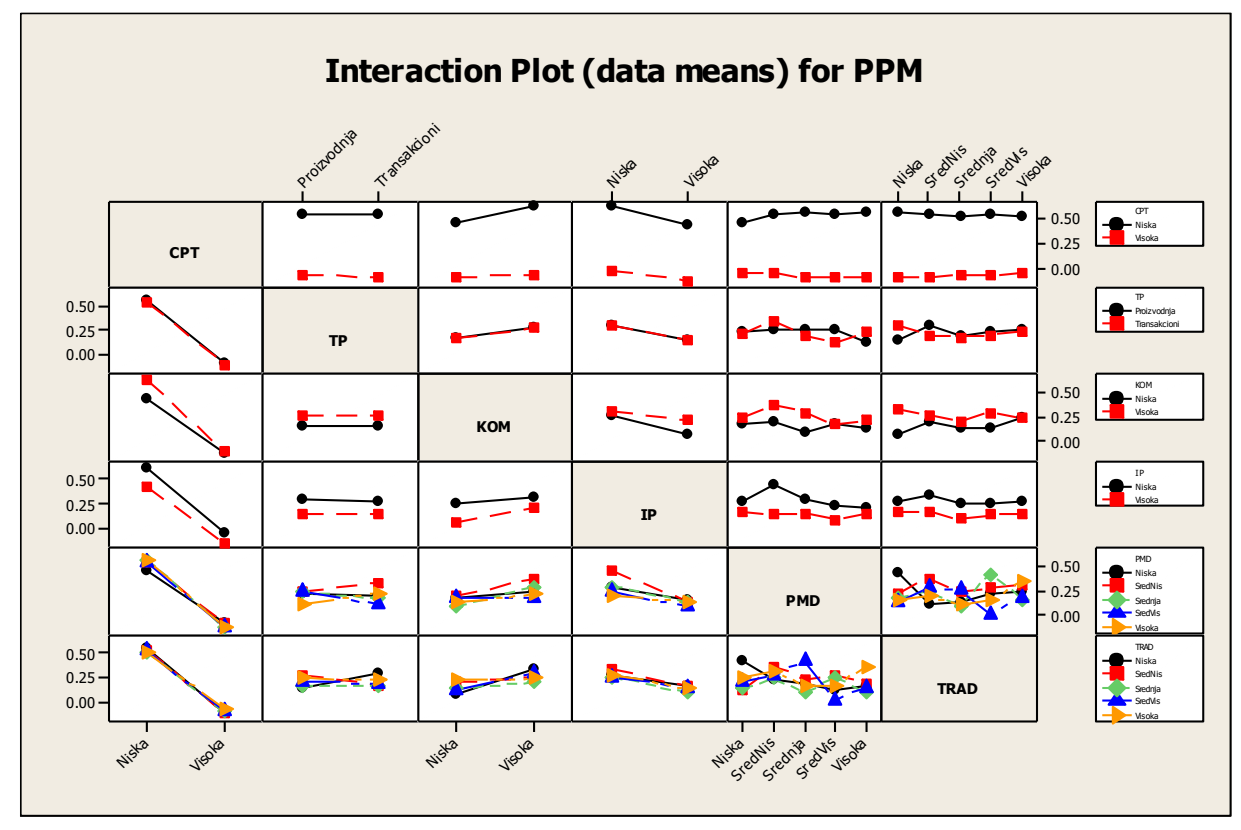

Fig. 12. Interaction plot PPM

The Main effects plot for "Total" with discrete PM and TRA values is presented in Fig. 13. From the "Total" Main Effects plot graph we can conclude that CPT has the most significant influence on defect reduction "Total" (sigma level), while Project type TP, PMD I TRAD have a relatively small impact on the "Total" value. In addition, right project selection IP and project complexity KOM have an influence on "Total", however that influence is less significant than of CPT. The Interaction plot is presented in Fig. 14.

The objective of Lean Six Sigma database development was to provide management support for implementation of the Lean Six Sigma strategy. Significant factors for successful implementation of the Lean Six Sigma initiative-identified during literature review-were utilized for data base development. During Lean Six Sigma implementation, data were collected and then analysed using MANOVA and GLM statistical methods. Results of statistical analysis were presented in the developed model that describes on time project completion (ZAV), achieved financial results (FIN), expected sigma level (PPM) and overall project success (Total). 
International Journal of Mathematical, Engineering and Management Sciences

Vol. 2, No. 2, 85-109, 2017

https://dx.doi.org/10.33889/IJMEMS.2017.2.2-009

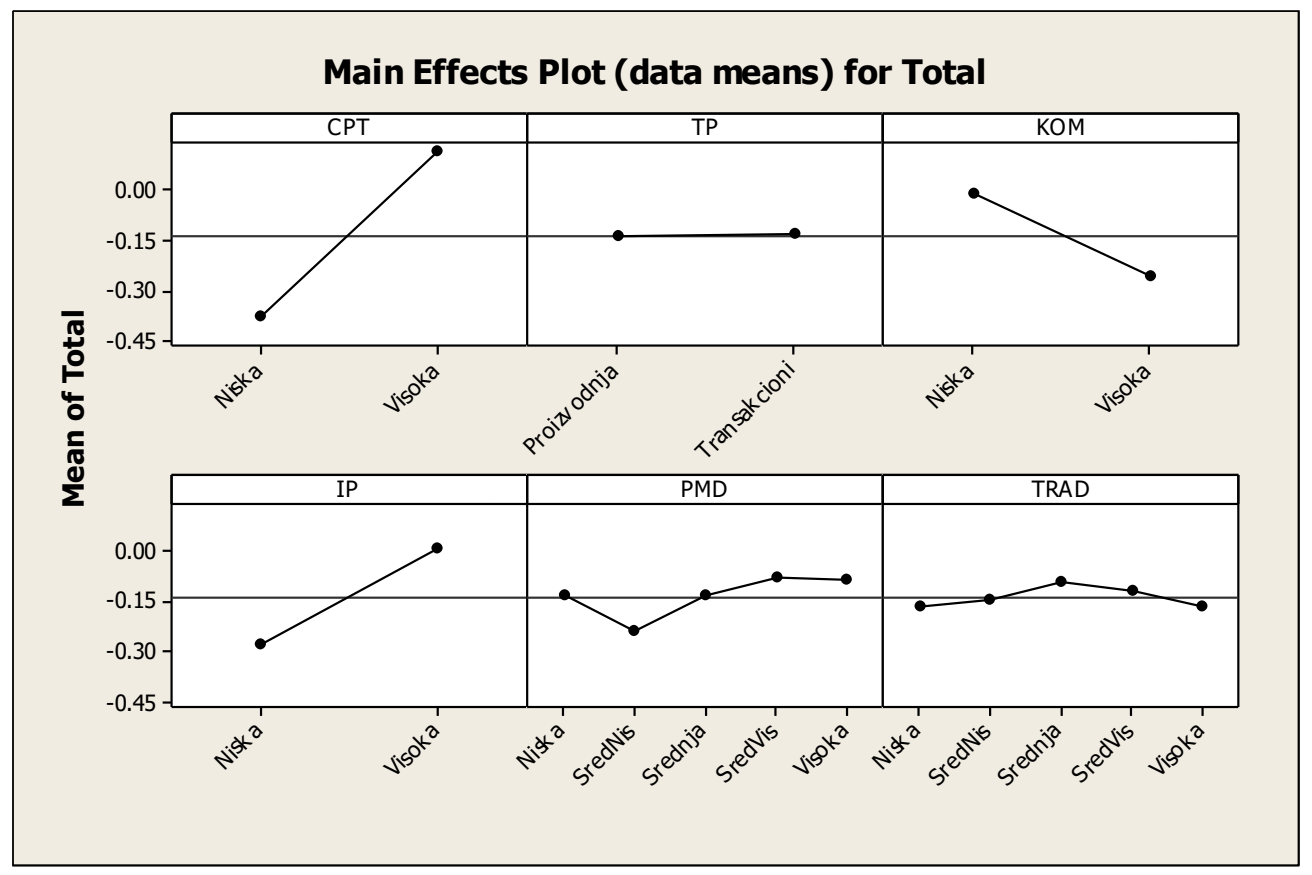

Fig. 13. Main effects plot for "Total"

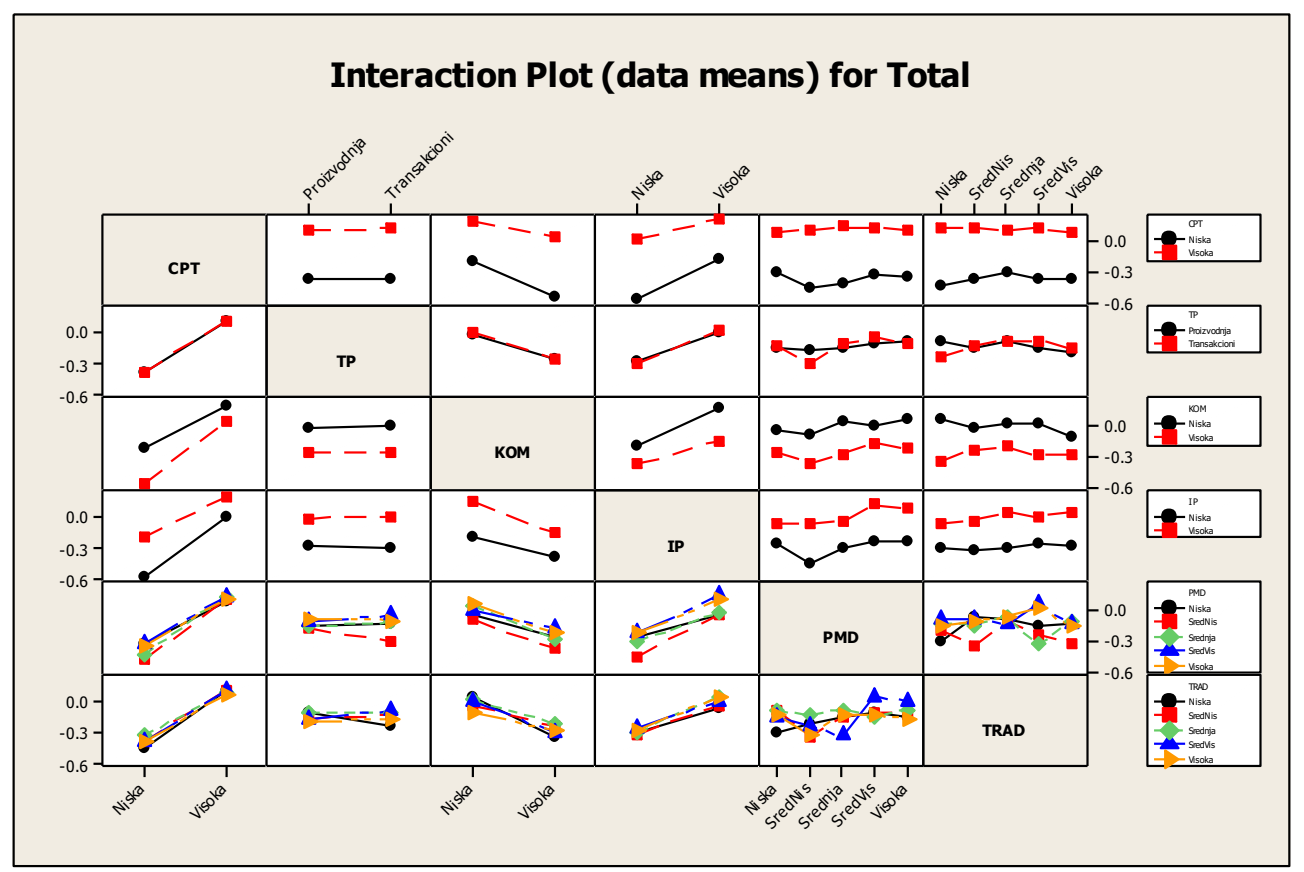

Fig. 14. Interaction plot for "Total" 
International Journal of Mathematical, Engineering and Management Sciences

Vol. 2, No. 2, 85-109, 2017

https://dx.doi.org/10.33889/IJMEMS.2017.2.2-009

\section{Conclusion}

Based on empirical data, we have presented the model and identified significant factors for Lean Six Sigma implementation. We have presented variety of different views, that which implementation factors that are significant - critical - for Lean Six Sigma implementation based on literature review. This diversity is caused by different definition and implementation approaches that organizations are taking, along with other industry, market, sector, or other distinctive characteristics. While there are many factors that are unique to specific authors and/or implementations, the majority of them agree that selection of the Black Belts, management support and project selection are the key process input variables (KPIV) that significantly determine success of Lean Six Sigma implementation and achievement of financial goals. Based on literature we have selected for our research as independent input- factors: Black Belt selection (CPT) based on their competence, management support (PM) and project selection (IP). Project selection was further defined using project type (TP), project complexity (KOM), project effort (TP). For the model output, we have selected project on time completion (ZAV), financial goals achieved (FIN), sigma level achieved that was measured using (PPM), and overall project success (Total). For statistical analysis, we have used Minitab software. Data were normalized relative to Lean Six Sigma implementation timeline in order to reduce the impact of Black Belt maturity growth. Financial results achieved values were presented relative to planned financial results; Planned sigma value (PPM) were presented relative to planned (PPM) respectively. Empirical results, which were collected during Lean Six Sigma implementation in 39 business units of the Intier Interiors Automotive Company in North America and Europe, were analysed using MANOVA and GLM, and results of the statistical analysis were presented.

\section{References}

Adams, C. W., Gupta, P., \& Wilson, C. E. (2003). Six sigma deployment (Vol. 4). Routledge.

Basu, R., \& Wright, J. N. (2003). Quality beyond six sigma. Butterworth Heinemann, Oxford, MA.

Box, G. E. P., Hunter, W. G., \& Hunter, J. S. (1978). Statistics for experimenters: an introduction to design, data analysis, and model building (p. 319). New York: Wiley.

Brue, G. (2000). Six Sigma for Leadership. Creative designs inc, Albuquerque, New Mexico.

Brue, G. (2002). Six Sigma for managers. McGraw-Hill.

Cobb, C. G. (2003). From quality to business excellence: A systems approach to management. ASQ Quality Press.

Cochran, W. G. (1977). Wiley series in probability and statistics: sampling techniques, John Wiley and Sons Inc., New York.

Cook, H. E. (2005). Design for Six Sigma as strategic experimentation: value, cost, pace of innovation, ASQ Quality Press, Milwaukee.

Covey, S. R. (1990). The seven habits of highly effective people, Simoon and Schuste, New York.

Dushmare, D. (2001). Six Sigma survey: breaking through Six Sigma hype, Quality Digest, Retrieved on November, 2001.

Dushmare, D. (2003). Six Sigma survey, Quality Digest, Retrieved on February, 2003.

Dushmare, D. (2003). Survey: Six Sigma packs a punch quality digest, Retrieved on November, 2003.

Dushmare, D. (2004). Got Six Sigma on the brain: our Six Sigma survey will show you what like minded quality professionals think about it, Quality Digest, Retrieved on November, 2004. 
International Journal of Mathematical, Engineering and Management Sciences

Vol. 2, No. 2, 85-109, 2017

https://dx.doi.org/10.33889/IJMEMS.2017.2.2-009

George, M. (2002). Lean Six Sigma: combining Six Sigma quality with lean speed, McGraw-Hill, New York.

George, M. (2003). Lean Six Sigma: Combining Six Sigma for Service: how to use lean speed and Six Sigma Quality to improve services and transactions, McGraw-Hill, New York.

Goldstein, M. (2001). Six Sigma program success factors. In Six Sigma Forum Magazine (Vol. 1, No. 1). ASQ.

Harry, M. (1994). The vision of Six Sigma: a roadmap for breakthrough Sigma, Publishing Company, Phoenix, Arizona.

Harry, M. (1994). The vision of Six Sigma: tools and methods for breakthrough Sigma, Publishing Company, Phoenix, Arizona.

Harry, M. (2001). Six Sigma knowledge design, Palladyne Publishing, Phoenix.

Martin, J. N. (2000). System engineering guidebook: a process for developing systems and products, CRC Press, Boca Raton.

Mladjenovic, M. (2003). Six Sigma success strategy, second international working conference: total quality management - advanced and integrated approaches, Kragujevac, Serbia.

Mladjenovic, M. (2005). Investigations the factors of successful continual quality improvement on the base strategy Six Sigma application, PhD Thesis, Faculty of Technical Sciences, Cacak, Serbia.

Montgomery, D. C. (2001). Design and analysis of experiments, John Wiley and Sons Inc., New York.

Ohno, T. (1988). Toyota production system, CT, Productivity Press, Stanford.

Rother, M., \& Shook, J. (2003). Learning to see: value stream mapping to add value and eliminate muda. Lean Enterprise Institute.

Schmidt, S. R., Kiemele, M. J., \& Berdine, R. J. (1999). Knowledge based management: Unleashing the power of quality improvement. Air Academy Pr.

Spanyi, A., \& Wurtzel, M. (2003). Six Sigma for the rest of us. Quality Digest, 23(7), 22-44.

Truscott, W. (2003). Six Sigma, continual improvement for businesses, Butterworth Heinemann, Oxford, MA.

Truscott, W. T., \& Truscott, W. G. (2003). Six sigma: continual improvement for business: a practical guide. Routledge.

Young, J. (2001). Driving performance results at American Express, Six Sigma Forum Magazine, 1(1), pp. 19-27. 